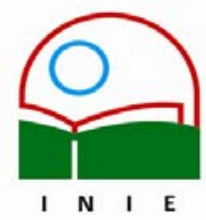

Actualidades Investigativas en Educación

Revista Electrónica publicada por el

Instituto de Investigación en Educación

Universidad de Costa Rica

ISSN 1409-4703

http://revista.inie.ucr.ac.cr

COSTA RICA

\title{
AUTOESTIMA: UN FACTOR RELEVANTE EN LA VIDA DE LA PERSONA Y TEMA ESENCIAL DEL PROCESO EDUCATIVO
}

SELF-ESTEEM: RELEVANT ASPECT IN A PERSON'S LIFE AND ESSENTIAL TOPIC IN

THE EDUCATIONAL PROCESS

Volumen 7, Número 3

pp. 1-27

Este número se publicó el 15 de diciembre 2007

María Luisa Naranjo Pereira

La revista está indexada en los directorios:

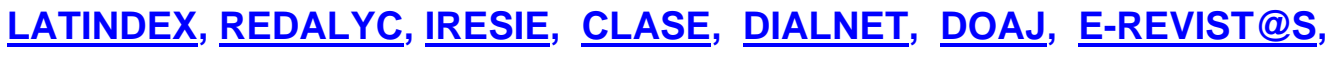

La revista está incluida en los sitios:

REDIE, RINACE, OEI, MAESTROTECA, HUASCARAN 


\title{
AUTOESTIMA: UN FACTOR RELEVANTE EN LA VIDA DE LA PERSONA Y TEMA ESENCIAL DEL PROCESO EDUCATIVO. SELF-ESTEEM: RELEVANT ASPECT IN A PERSON'S LIFE AND ESSENTIAL TOPIC IN THE EDUCATIONAL PROCESS
}

\author{
María Luisa Naranjo Pereira ${ }^{1}$
}

\begin{abstract}
Resumen: Este artículo trata sobre la autoestima como un aspecto de enorme relevancia en la vida de la persona, por cuanto contribuye a que su existencia sea más satisfactoria. La estima propia es una necesidad humana, configurada por factores tanto internos como externos, un proceso dinámico y multidimensional que se construye y reconstruye a lo largo del ciclo vital. En el ámbito concreto de la educación, se considera que facilitar el logro de una estima positiva debe ser el propósito más alto del proceso educativo.

Se analiza la relación entre la autoestima y el autoconcepto y como ambos se vinculan con variables relacionadas con las actitudes de la población estudiantil hacia las actividades académicas y el éxito escolar. Se estudia asimismo los diversos componentes de la autoestima: autoimagen, autovaloración, autoconfianza, autocontrol, autoafirmación, autorrealización y las metas de superación personal en cada componente.

Se hace referencia al tema de las características y actitudes de las personas con una alta o una baja autoestima y los factores vinculados con éstas. Se incluye también los temas de la influencia de las distorsiones cognitivas y de personas significativas en la construcción de la autoestima y finalmente se enfatiza en la relación entre autoestima y resultados educativos.
\end{abstract}

Palabras claves: AUTOESTIMA/ EDUCACIÓN/ COMPONENTES/ CARACTERÍSTICAS/ DISTORSIONES COGNITIVAS.

\begin{abstract}
This paper deals with self-esteem as an aspect of great relevance in the life of each person, as it contributes to a satisfying existence. Self-esteem is a human need, it is comprised of internal and external factors, resulting in a dynamic and multidimensional process that is built and rebuilt along the life cycle. In the field of Education, providing the means for students to achieve a positive self-esteem should be a major goal.

The relationship between self-esteem and self-concept is analyzed, as well as the ways in which both interact with students' attitudes towards academic activities and school success. In addition, the following components of selfesteem and personal development goals for each of them are studied: self-image, self-worth, self-confidence, selfcontrol, self-assertion, and self-actualization.

Characteristics and attitudes of persons with high or low self-esteem and the factors associated with those, are mentioned. The influence of cognitive distortions and significant others in the construction of a person's selfesteem are also included. The relationship between self-esteem and achievement is emphasized.
\end{abstract}

Keywords: SELF-ESTEEM/ EDUCATION/ COMPONENTS/ CHARACTERISTICS/ COGNITIVE DISTORTIONS

\footnotetext{
1 Licenciada en Ciencias de la Educación con énfasis en Orientación, Profesora de Psicología, ambos títulos de la Universidad de Costa Rica. Profesora de la Escuela de Orientación y Educación Especial en la Universidad de Costa Rica, durante los últimos 22 años. Ha publicado diversos artículos relacionados con el Desarrollo Humano y la superación personal $y$ tres libros de texto: Enfoques conductistas, cognitivos y racional-emotivos, Enfoques humanísticos-existenciales y un modelo ecléctico, y Estrategias para la Orientación de la niñez.
}

Correo electrónico: mlnaranjo@costarricense.cr

Artículo recibido: 17 de julio, 2007

Aprobado: 23 de noviembre, 2007 


\section{Autoestima.}

La autoestima es un factor importante a considerar en la vida de las personas en general y en particular, en el tema del desempeño y de las actitudes hacia las actividades académicas de los estudiantes y las estudiantes. De acuerdo con Rice (2000), la autoestima de una persona es la consideración que tiene hacia sí misma. Señala este autor que ha sido denominada como el vestigio del alma y que es el ingrediente que proporciona dignidad a la existencia humana.

La autoestima se desarrolla a partir de la interacción humana, mediante la cual las personas se consideran importantes una para las otras. El yo evoluciona por medio de pequeños logros, los reconocimientos y el éxito.

En opinión de Maslow, citado por Santrock (2002), la mayoría de las personas que no han desarrollado un alto nivel de estima, nunca llegan a autorrealizarse. De Mezerville (2004), menciona que Abraham Maslow ha sido uno de los representantes de la psicología humanista quien más ha difundido el papel que la autoestima desempeña en la vida de la persona, al incluirla dentro de su conocida jerarquía de necesidades. Para Maslow existen dos tipos de necesidades de estima, la propia y aquella que proviene de las otras personas. Ambas necesidades las ubica jerárquicamente por encima de las necesidades fisiológicas, las de seguridad personal y las de amor y pertenencia.

Branden, en de Mézerville (2004, p. 25) manifiesta que:

La autoestima está configurada por factores tanto internos como externos. Entiendo por factores internos, los factores que radican o son creados por el individuo-ideas, creencias, prácticas o conductas. Entiendo por factores externos los factores del entorno: los mensajes transmitidos verbal o no verbalmente, o las experiencias suscitadas por los padres, los educadores, las personas significativas para nosotros, las organizaciones y la cultura.

Según Güell y Muñoz (2000, p. 118), la persona tiene la capacidad de establecer su propia identidad y atribuirse un valor y, a esa valoración se le llama autoestima. Señala que "Si conseguimos mantener un buen nivel de autoestima resistiremos las críticas, nos abriremos mejor a los demás, aprenderemos a pedir ayuda y, en general, nos resultará 
mucho más gratificante vivir, lo que contribuirá también a prevenir cualquier proceso depresivo".

Refiriéndose a este tema de la autoestima, Santrock (2002, p. 114) expresa que ésta es: "La evaluación global de la dimensión de Yo o self. La autoestima también se refiere a la autovalía o a la autoimagen, y refleja la confianza global del individuo y la satisfacción de sí mismo".

Para White en Courrau (1998), la autoestima es el valor del yo, el valor de la persona ante los ojos de las otras. Esta autora la define como un proceso dinámico y multidimensional que se va construyendo a lo largo de la vida y en el cual se involucra el contexto social, físico, emocional y cognitivo de la persona.

Al respecto también Molina en Olivares (1997, p. 20) considera que la autoestima tiene un significado complejo, y que precisa de cuatro componentes en su definición:

- Es una actitud, ya que contempla las formas habituales de pensar, actuar, amar y sentir de las personas para consigo mismas.

- Tiene un componente cognitivo, pues se refiere a las ideas, opiniones, creencias percepciones y procesamiento de la información que posee la persona respecto de sí misma.

- Tiene un componente afectivo, que incluye la valoración de los positivo y negativo, involucra sentimientos favorables y desfavorables, agradables o desagradables que las personas perciben de sí mismas.

- Tiene un componente conductual, porque implica la intención y decisión de actuar, de llevar a la práctica un comportamiento consecuente y coherente.

Por otra parte, Gastón de Mézerville (204, p. 61) menciona que "La autoestima es la percepción valorativa y confiada de sí misma, que motiva a la persona a manejarse con propiedad, manifestarse con autonomía y proyectarse satisfactoriamente en la vida".

Alcántara en Molina, Baldares y Maya (1996, p. 24) expresa: 
La autoestima es la meta más alta del proceso educativo y quicio y centro de nuestra forma de pensar, sentir y actuar, es el máximo resorte motivador y el oculto y verdadero rostro de cada hombre esculpido a lo largo del proceso vital.

Este autor considera también que la autoestima no es innata, que se adquiere y se genera como resultado de la historia de cada persona. Este aprendizaje generalmente no es intencional, por cuanto se moldea a la persona desde diversos contextos informales educativos. No obstante, a veces es el resultado de una acción intencional para lograr su consecución.

Las ideas anteriores pueden relacionarse con la neurociencia, específicamente con algunos de los principios de aprendizaje del cerebro. Algunos de estos principios son señalados por Caine y Caine, en Salas (2003). Entre estos pueden mencionarse:

- El cerebro es un complejo sistema adaptativo. Pensamientos, emociones, imaginación, predisposiciones y fisiología operan concurrente e interactivamente en la medida en que todo el sistema interactúa e intercambia información con su entorno.

- El cerebro es un cerebro social. Las personas empiezan a ser configuradas a medida que sus cerebros receptivos interactúan con el entorno y se establecen relaciones interpersonales. Está claro que a lo largo de la vida los cerebros cambian en respuesta a los compromisos con las demás personas, de tal modo que estas pueden ser vistas siempre como partes integrales de sistemas sociales más amplios. En realidad, parte de la propia identidad depende del establecimiento de una comunidad y de la posibilidad de pertenecer a esta. En consecuencia el aprendizaje y el desarrollo de la autoestima están influidos por la naturaleza de las relaciones sociales dentro de las cuales se encuentran las personas.

- La búsqueda de significado es innata. En lo esencial, la búsqueda de significado está dirigida por metas y valores personales. La búsqueda de significado se ordena desde la necesidad de alimentarse y encontrar seguridad, mediante el desarrollo de las relaciones interpersonales y de un sentido de identidad, hasta una exploración del propio potencial y búsqueda de lo trascendente.

- El aprendizaje implica tanto una atención focalizada como una percepción periférica. Es decir, el cerebro absorbe información de lo que está directamente consciente, y también de lo que se encuentra más allá del centro inmediato de atención. Incluso las 
señales inconscientes que revelan actitudes y creencias interiores tienen un efecto poderoso en las personas.

- El aprendizaje es un proceso de desarrollo. En muchos aspectos, no existe el límite para el crecimiento ni para las capacidades de los seres humanos para aprender más las neuronas siguen siendo capaces de realizar y reforzar nuevas conexiones a lo largo de toda la vida.

De igual manera, a pesar de que la autoestima es una estructura consistente y estable y a veces difícil de cambiar, su naturaleza es dinámica, por lo que puede crecer, empobrecerse o incluso desintegrarse. Lo importante es que, en mayor o menor grado es perfectible.

\section{Relación entre autoconcepto y autoestima.}

De acuerdo con Rice (2000), el autoconcepto es la percepción cognitiva consciente y la evaluación que las personas realizan sobre sí mismas, son sus pensamientos acerca de sí mismas. Señala que según Wayment y Zetlin, el autoconcepto es la identidad autohipotetizada de la persona y que Erikcson se refiere a él como la identidad del yo o el yo autopercibido, la individualidad consistente. Debería describirse como un sistema de actitudes que la persona tiene hacia sí misma, supone la suma total de sus autodefiniciones o autoimágenes.

Refiriéndose a los adolescentes y a las adolescentes, explica este autor que ellos y ellas recogen datos que les permiten evaluarse. Desde la evidencia se plantean hipótesis sobre sí mismos y sobre sí mismas y examinan sus sentimientos y opiniones mediante sus experiencias y relaciones. Además, establecen comparaciones de su persona con sus propios ideales y los de otras personas.

Se menciona que todas las personas tienen seis aspectos del yo: lo que realmente son, lo que piensan que son, lo que piensan otras que son, lo que creen que piensan las demás de ellas, lo que quieren llegar a ser y las expectativas que creen que otras personas tienen sobre ellas. Los autoconceptos pueden o no tener enfoques cercanos a la realidad, y están permanentemente en proceso de cambio. 
Strang, citado por Rice (2000), propone que existen cuatro dimensiones básicas del yo, las cuales explica de la siguiente manera. En primer lugar, está el autoconcepto básico, que es la visión del adolescente y la adolescente sobre su personalidad y las percepciones sobre sus habilidades, su estatus y sus funciones en el mundo exterior.

Posteriormente, están los autoconceptos temporales o transitorios de la persona. Estas ideas sobre el sí misma, están influidas por el estado de ánimo del momento o por una experiencia reciente. Por ejemplo, la obtención de una puntuación baja en una prueba reciente, puede hacer que la persona se sienta temporalmente poco capaz; en este caso, una crítica aguda por parte de otra persona puede producir un sentimiento transitorio de una autoestima devaluada.

En tercer lugar, está el yo social; esto es, la opinión que creen que otras personas tienen sobre ellas, que a su vez influye sobre ellas mismas. Si tienen la impresión de que otras personas piensan que son incapaces o socialmente inaceptables, pensarán sobre sí mismas de forma negativa. Harter, Stocker y Robinson en este autor, mencionan que la identidad proviene, en parte, de la implicación del yo con las otras personas, la intimidad, la participación en grupo, la cooperación y la competencia. De esta forma, las percepciones sobre los pensamientos de las demás personas impregnan las visiones sobre sí mismas.

La cuarta dimensión es el yo ideal; es decir, qué tipo de personas les gustaría ser. Las aspiraciones pueden ser realistas, demasiado bajas o demasiado altas. Los yo ideales que demasiado bajos impiden la realización, mientras que lo que son muy altos pueden llevar a la frustración y autodesprecio. Los conceptos del yo que son realistas conducen a la autoaceptación, la salud mental y la consecución de metas realistas.

Explica Rice (2000) que habiendo construido conceptos sobre sí mismos y sobre sí mismas, las personas adolescentes deben enfrentarse a la estima que tienen de sí. Cuando su autoconocimiento las lleva a la autoaceptación y a la aprobación, a un sentimiento de valía, entonces tienen autoestima suficiente como para aceptarse a sí mismos y a sí mismas. Para que las personas se autoestimen, debe existir una correspondencia entre los conceptos de sí mismas y los yo ideales. 
Al inicio de la pubertad, la mayoría de los jóvenes y de las jóvenes empiezan a realizar evaluaciones de sí, comparando aspectos tales como los físicos, las habilidades motoras, las capacidades intelectuales y las habilidades sociales con los de sus iguales y con los de sus ideales o héroes. Esta autoevaluación crítica podría acompañarse de un sentimiento de vergüenza que hace a las personas adolescentes vulnerables a la crítica y al ridículo. Como resultado, se preocupan por intentar reconciliar el yo percibido con su yo ideal. Durante la adolescencia tardía, puede que hayan logrado organizar su yo, percibiendo lo que pueden ser con mayor efectividad e integrando sus metas en sus yo ideales.

Rogers citado por este autor, señala que existe una ausencia de conflicto interno y de ansiedad cuando las personas descubren quienes son, y lo que perciben que son y lo quieren ser comienza a converger, entonces pueden aceptarse a sí mismas sin conflictos. Sus autopercepciones y las relaciones con otras personas llevan a la autoaceptación y a la autoestima. Por otra parte, el desajuste psicológico ocurre cuando hay una divergencia entre el yo real y el yo en relación con otras personas, con respecto al yo que le gustaría ser.

Beane (1986) indica que los estudios han demostrado una relación persistente entre el autoconcepto y la autoestima y diversas variables relacionadas con las actividades académicas. Por ejemplo, los estudiantes y las estudiantes con autoconceptos claros y una autoestima positiva tienden a participar más, a tener puntajes de competencia educativa más altos, a exhibir una conducta prosocial y a demostrar un logro académico mayor que el que tienen sus iguales con autopercepciones no claras o negativas.

En otras palabras, aquellos estudiantes y aquellas estudiantes que creen que pueden tener éxito en la institución educativa, realmente tienen éxito. Los éxitos continuos conducen a estas personas a una mayor estabilidad en la autoconfianza educativa; inversamente, aquellas personas que fracasan experimentan una pérdida de autoestima, lo cual, a su vez, contribuye a una continua carencia de éxito. La autoconfianza en el aprendizaje es la clave para ser exitoso o exitosa en la educación.

Por su parte, también Borden y Stone (1982, p. 251), manifiestan que:

Una de las principales variables en la formación del concepto de uno mismo es el desarrollo de una elevada autoestima. Para lograrlo es necesario convencerse y tener 
fe en las propias habilidades. Sus decisiones deben proceder de sus ideas y usted debe estar dispuesto a asumir la responsabilidad de sus actos.

En los modelos de autoactualización de Maslow y Rogers, citados por los autores mencionados, la persona saludable está en proceso continuo de intentar comprender los sentimientos, las percepciones y las motivaciones de su conducta personal. No obstante, este proceso de autocuestionamiento ocurre dentro del contexto de un sentido básico de adecuación. Su posición ante la vida parece ser: básicamente me gusto a mi mismo o a mi misma aún cuando no soy perfecto o perfecta.

Otra verdad que parece ser que muchas personas no están totalmente enteradas de todas las creencias que tienen sobre sí mismas. Algunas tienen autoimágenes y autoestimas altamente desarrolladas, mientras que otras solo tienen una autoimagen y estima mal acabada e inarticulada en sí misma. Existe una actividad estructurada conocida como: ¿quién soy yo?, que ilustra esta observación, señalan Eisenberg y Patterson (1981). Para realizar esta actividad se requiere dos personas participantes, una que pregunta y una que responde. La persona que pregunta simplemente repite el cuestionamiento: ¿quién es usted? Con cada cuestión, la persona que responde debe dar una nueva descripción de sí misma. Se ha encontrado que la mayoría de las personas se describen a sí mismas por los roles familiares, educativos o vocacionales que desempeñan. Relativamente pocas responden a más de diez preguntas y muchas no pueden dar autodescripciones más allá de sus roles.

Aunque algunos aspectos de las creencias y percepciones de una persona acerca de sí misma no están fácilmente disponibles en la consciencia, señalan estos autores, las creencias sobre sí siempre parecen actuar como poderosos determinantes de la conducta. Las personas a las que no les gusta su yo, con frecuencia tienen una baja autoestima y están motivadas para evitar el fracaso, mientras que las personas que gustan de sí mismas a menudo tiene una buena autoestima y están motivadas hacia las experiencias de éxito.

Teorías como las de Eisenberg y Patterson (1981) enfatizan que el aumento de la consciencia de una persona acerca de y el conocimiento del yo es una clave central para estimular el crecimiento, la toma de decisiones efectiva, su autopercepción y el cambio de conducta. 
Refiriéndose concretamente a los estudiantes y las estudiantes, Lee (1986) indica que existe una cantidad considerable de evidencia empírica que demuestra que el autoconcepto predice e influencia los logros en los centros educativos, desde los grados de primaria hasta la educación universitaria. Algunas contribuciones importantes para el autoconcepto lo aportan el éxito alcanzado previamente, la percepción que el profesor o la profesora tenga de la habilidad y el valor del estudiante o la estudiante, la aceptación de sus iguales y dentro del grupo. Debido entonces a que los desarrollos educativos y psicológicos parecen ser interdependientes, es importante determinar y promover las variables productoras de cambios relacionados con las experiencias afectivas que mejoran la autoconcepción de los estudiantes y las estudiantes y por ende su autoestima.

Stafford y Hill (1989) enfatizan también la idea de que la forma en que se perciben las personas a sí mismas podría tener una futura influencia en el éxito que puedan lograr en la institución educativa, pero también y quizá más importante como personas totales.

Alcántara en Molina, Baldares y Maya (1996, p. 25) se refiere al autoconcepto, definido como la opinión que se tiene de la propia personalidad y su conducta y el cual ocupa un lugar importante en el desarrollo y la consolidación de la autoestima. Señala este autor que:

Las restantes dimensiones, afectiva y conductual, caminan bajo la luz que les proyecta el autoconcepto, que a su vez se hace servir y acompañar por la autoimagen o representación mental que un sujeto tiene de sí mismo en el presente y en las aspiraciones y expectativas futuras.

\section{Componentes de la autoestima.}

De acuerdo con Gastón de Mézerville (2004) existen una serie de aspectos interrelacionados que componen la autoestima. A partir de esta concepción, presenta un modelo propio al que ha denominado proceso de la autoestima. En este, se considera a la autoestima según dos dimensiones complementarias, una actitudinal inferida integrada por tres componentes: la autoimagen, la autovaloración y la autoconfianza; y una dimensión conductual observable conformada por otros tres componentes: el autocontrol, la autoafirmación y la autorrealización. 
A continuación se presenta una síntesis de este proceso de la autoestima y sus respectivos componentes, siguiendo las explicaciones de este autor.

Sobre el primer componente, la autoimagen, consiste en la capacidad de verse a sí mismo o a sí misma como la persona que realmente es, con sus virtudes y defectos. La persona que tiene una autoestima saludable trata de estar conciente incluso de sus errores, por cuanto la autoestima no se vincula con ser perfecto o ser perfecta.

Se trata de lograr una percepción básica de las características más relevantes de la propia personalidad, su relación con otras personas y con el ambiente.

La autoimagen no es un aspecto estático, incluye el conocimiento propio basado en experiencias pasadas, al igual que las concepciones que la persona va elaborando sobre su posible evolución futura.

Generalmente los problemas de autoestima se asocian con una baja autoimagen; no obstante, también es posible que una autopercepción de superioridad señale dificultades en este aspecto, dando como resultado lo que se denomina pseudoautoestima. Al respecto, Branden citado por de Mézerville (2004, p. 31) señala "La arrogancia, la jactancia y la sobreestimación de nuestras capacidades refleja más bien una autoestima equivocada y no, como imaginan algunos, un exceso de autoestima".

Las metas por lograr, respecto de la autoimagen, consisten en la búsqueda de un autoconocimiento que le permita a la persona aumentar su capacidad de percibir, de manera equilibrada, tanto los aspectos positivos como negativos de su personalidad.

Respecto del segundo componente, la autovaloración, consiste en que la persona se considere importante para sí misma y para las demás. La autovaloración se relaciona con otros aspectos como la autoaceptación y el autorespeto y significa que se percibe con agrado la imagen que la persona tiene de sí.

Branden en de Mézerville (2004, p. 34) designa la autovaloración como el respeto a uno mismo o a una misma y la de define como: 
La confianza en nuestro derecho a triunfar y a ser felices, el sentimiento de ser respetables, de ser dignos y de tener derecho a afirmar nuestras necesidades y carencias, a alcanzar nuestros principios morales y a gozar del fruto de nuestros esfuerzos.

La meta en el aspecto de la autovaloración consiste entonces en identificar aquellos medios adecuados que satisfagan la necesidad que tiene la persona de verse a sí misma en forma positiva, de tal manera que le otorgue mayor valor y atención a las dimensiones realmente importantes de su personalidad.

Sobre el tercer componente, la autoconfianza, se señala que ésta se caracteriza porque la persona cree que puede realizar bien distintas cosas y sentirse segura al hacerlas. Esta percepción interna favorece una buena autoestima, sentirse cómodo o cómoda en la relación con otras personas y manifestarse con espontaneidad. La autoconfianza se traduce en que la persona crea en sí misma y en sus propias capacidades para enfrentar distintos retos, lo que a su vez la motiva a buscar oportunidades que le permitan poner en práctica y demostrar sus competencias.

La meta de superación personal en el aspecto de la autoconfianza consiste en desarrollar una actitud realista de creencia en sí mismo o en sí misma y en sus propias capacidades, en la voluntad de ejercitarlas adecuadamente y disfrutar al hacerlo.

En cuanto al cuarto componente, el autocontrol, se menciona que consiste en manejarse adecuadamente en la dimensión personal, cuidándose, dominándose y organizándose bien en la vida. Significa la capacidad de ordenarse apropiadamente y ejercer un dominio propio que fomente tanto el bienestar personal como el del grupo al que se pertenece. Por lo tanto, el término autocontrol incluye otros aspectos, tales como el autocuidado, la autodisciplina, la organización propia o el manejo de sí mismo o de sí misma.

La capacidad de autocontrol con frecuencia se ve limitada en aquellas personas con una baja autoestima. Esta falta de capacidad se manifiesta en una situación de descontrol en diversas áreas, tales como el autocuidado, el manejo de las emociones, las relaciones 
interpersonales, los hábitos de trabajo, de estudio o de la vida en general y la falta de habilidad para organizar acciones en pro del logro de metas deseadas.

La meta de superación en este aspecto del autocontrol consiste en adoptar destrezas adecuadas de cuidado personal y patrones de comportamiento caracterizados por una buena disciplina y organización existencial.

Sobre el quinto componente, la autoafirmación, se define como la libertad de ser uno mismo o una misma y poder tomar decisiones para conducirse con autonomía y madurez. Se caracteriza por la capacidad que tiene la persona de manifestarse abiertamente cuando expresa sus pensamientos, deseos o habilidad. Además, incluye otras capacidades tales como la autodirección y la asertividad personal.

Las personas que no se aprecian lo suficiente y valoran poco sus capacidades y cualidades, con frecuencia se abstienen de participar o de decidir, debido al temor que les provoca el poder equivocarse frente a otras personas. Este tipo de comportamiento las conduce a anularse ante las oportunidades de expresar sus opiniones y talentos.

La misma situación ocurre con las personas que buscan en exceso la aprobación de otras. Al no sentirse capaces de manifestar lo que realmente piensan y sienten, se dejan conducir por la presión social, llegando incluso a incurrir en conductas autodevaluativas. Distinto es el caso de quienes procuran sentirse satisfechas consigo mismas, pues aún a riesgo de que sus ideas o acciones puedan ser desaprobadas, las manifiestan, logrando con ello una autoestima saludable.

La meta de superación en el componente de la autoafirmación, consiste en encontrar formas saludables de expresar el pensamiento y las habilidades ante las demás personas y en conducirse de manera autónoma, sin llegar a los extremos de sobredependencia o autosuficiencia exagerada.

Respecto del último componente de la autoestima, la autorrealización, de Mézerville explica que consiste en el desarrollo y la expresión adecuada de las capacidades, de modo que la persona pueda vivir una vida satisfactoria y de provecho para sí misma y para otras 
personas. Implica la búsqueda del cumplimiento de las metas que conforman el proyecto vital de su existencia.

Las personas que gozan de una buena autoestima, tienden a manifestar dos características de la verdadera autorrealización; por una parte, que sus metas sean significativas y por otra, que le permitan proyectarse personalmente, generando beneficio para sí y para otras personas y obteniendo satisfacción de ello.

Contrario a la situación anterior, las personas con baja autoestima generalmente se lamentan de su falta de realización personal y asocian esta queja con una sensación de estancamiento existencial.

Las metas por alcanzar en el aspecto de la autorrealización exigen que la persona se proyecte mediante distintas áreas de interés, aptitud o compromiso que le resulten significativas. Para lograr este propósito es necesario que descubra lo que le otorga verdadero sentido a su vida, que desarrolle sus capacidades y se plantee metas que promuevan la realización personal de su existencia.

\section{Alta y baja autoestima, factores vinculados y características.}

Eisenberg y Patterson (1981) se refieren a una serie de conductas correlacionadas tanto con la alta como con la baja autoestima. Entre ellas se mencionan: expectativas hacia el futuro, asertividad personal, estilos para enfrentar el estrés, locus de control, toma de riesgos, temor al fracaso y nivel de aspiraciones. Con base en lo planteado por estos autores, a continuación se hace referencia a las conductas mencionadas.

En primera instancia, se señala que existen dos razones por las cuales este tema es importante. Una es que la autoestima de una persona no se ve, sino que se elaboran conjeturas sobre ésta a partir de la conducta evidente. Estos patrones de conducta suministran datos a partir de los cuales se puede hacer inferencias diagnósticas razonables. La segunda razón es que a menudo algunos patrones de conducta pueden parecer extraños a primera vista; no obstante, si se les vincula con la autoestima subyacente, se puede comprender su significado. 
Coopersmith citado por Eisenberg y Patterson (1981), considera que las personas con alta, media y baja autoestima, tienen diferentes expectativas para el futuro, difieren respecto de la asertividad personal y tienen diferentes estilos básicos para enfrentar el estrés.

Se señala que las personas con una autoestima alta enfocan las tareas y a las otras personas con la expectativa de que serán exitosas y bien recibidas. Confían en sus percepciones y juicios y creen que pueden dirigir sus esfuerzos a soluciones favorables. Sus autoactitudes positivas les permiten aceptar sus propias opiniones y otorgar crédito y confianza a sus reacciones y conclusiones, lo cual a su vez le facilita seguir sus propios juicios cuando existe una diferencia de opinión y considerar ideas nuevas. Esa confianza en sí mismas, acompañada por sentimientos de justicia, es probable que les provean la convicción de que es correcta y las animen a expresar esas convicciones.

Por otra parte, las actitudes y expectativas que dirigen a la persona hacia una alta autoestima, a una mayor independencia y creatividad social, también la conducen a una acción social más asertiva y vigorosa. Es probable que sea más participativa que pasiva en los grupos de discusión, reporte menos dificultad estableciendo amistades y exprese opiniones aún cuando sepa que éstas pueden llevarla a una recepción hostil.

Molina, Baldares y Maya (1996, p. 30) describen a las personas con alta autoestima de la siguiente manera:

Una persona con alta autoestima no se considera a sí misma como el centro del universo y mejor que los demás y las demás. Simplemente conoce muchos aspectos de sí misma, tiene auto-respeto y tiene consciencia de su propio valor como persona única e irrepetible. Reconoce sus cualidades buenas, pero no se cree perfecta. Al contrario, puede ser que tenga mucha consciencia sobre sus defectos y del hecho de que ella comete errores. Pero no ve sus defectos y errores como representativos de alguien sin valor, ella los entiendo como representativos del ser humano.

La personalidad saludable a la que se refieren Jourard y Landsman (1987), podría decirse que corresponde a una persona con alta autoestima. Estos autores se refieren a ésta señalando que es la forma de actuar guiada por la inteligencia y el respeto por la vida, de tal modo que se satisfacen las necesidades personales y la persona crece en conciencia y suficiencia y en la capacidad para amarse a sí misma, a otras y al ambiente. Asimismo, 
una de sus características distintivas es una buena disposición para aceptar o enfrentar experiencias nuevas, su habilidad para responder a ideas, pensamientos o percepciones novedosas, lo cual es un indicio de conciencia de la persona.

Por su parte, Eisenberg y Patterson (1981) manifiestan que la mayoría de los autores concuerdan en que las personas saludables gustan de sí y se respetan, son tanto optimistas como realistas acerca de la estimación personal de su potencial, tienen una imagen realista de los atributos y habilidades personales, pueden experimentar orgullo honesto de sus logros y puede aceptar limitaciones sin culpa, vergüenza o desconcierto.

Rubin en Borden y Stone (1982), se refiere a las personas con alta estima como ganadoras, indicando que éstas se relacionan exitosamente consigo mismas y con las demás, lo que significa lograr una vida más plena, más gratificante y feliz en todas las áreas de la existencia y empresas humanas.

Otras características señaladas para estas personas son: les gusta estar solas y les gusta estar con otras personas; son felices con lo que son la mayoría del tiempo; escuchan a las demás, pero deciden por sí mismas, son capaces de ser firmes y no sienten la necesidad de someterse, revelarse o escapar; gozan el día de hoy y esperan con alegría el mañana; pueden dar y recibir amor; pueden tolerar la ira de las demás y mostrarse airadas ellas mismas; tienen más facilidad para perdonar y olvidar; son capaces de gozar su individualidad; pueden invertir emociones y entusiasmo en personas, causas y cosas; les importa este mundo y aprecian su papel y responsabilidad como parte de él.

El resultado de ser una persona con una alta autoestima y responsable de su propia vida, es ser una persona actualizadora de sí misma y autotrascendente. Al respecto García (2005), señala las siguientes características de una persona con una alta autoestima:

- Cree firmemente en ciertos valores y principios, está dispuesta a defenderlos aún cuando encuentre fuertes oposiciones y se siente lo suficientemente segura como para modificar esos valores y principios si nuevas experiencias indican que estaba equivocada.

- Es capaz de obrar según crea más acertado, confiando en su propio juicio, y sin sentirse culpable cuando a otras personas les parece mal lo que ha hecho. 
- No emplea demasiado tiempo preocupándose por lo que halla ocurrido en el pasado, ni por lo que pueda ocurrir en el futuro.

- Tiene confianza en su capacidad para resolver sus propios problemas, sin dejarse acobardar por los fracasos y dificultades que experimente.

- Se considera y realmente se siente igual, como persona, a cualquier otra, aunque reconoce diferencias en talentos específicos, prestigio profesional o posición económica.

- Da por supuesto que es una persona interesante y valiosa para otras, por lo menos para aquellas con quienes se relaciona.

- $\quad$ No se deja manipular por las demás personas, aunque está dispuesta a colaborar si le parece apropiado y conveniente.

- Reconoce y acepta en sí misma una variedad de sentimientos e inclinaciones tanto positivas como negativas y está dispuesta a revelarlas a otra persona si le parece que vale la pena.

- Es capaz de disfrutar diversas actividades como estudiar, jugar, trabajar, descansar, estar con amistades.

- Es sensible a las necesidades de otras personas, respeta las normas de convivencia generalmente aceptadas y reconoce sinceramente que no tiene derecho a mejorar o divertirse a costa de las demás personas.

De acuerdo con Rice (2000) una autopercepción positiva o una alta autoestima es una resultado deseado del proceso de desarrollo humano. Se le vincula con la salud mental a largo plazo y con el equilibrio emocional. Por otra parte, de acuerdo con Koenig, citado por este autor, las personas cuyas identidades son débiles o cuya autoestima no se ha desarrollado lo suficiente, manifiestan diversos síntomas de falta de salud emocional, tales como síntomas psicosomáticos de ansiedad.

En ocasiones, el adolescente o la adolescente con una identidad pobre y una baja autoestima intentan presentar una imagen falsa, una fachada con la cual enfrentarse al mundo. Se trata de un mecanismo de compensación empleado para superar el sentimiento de poca valía, tratando de esta manera de convencer a otras personas de que se es un ser valioso. No obstante, poner esta conducta en práctica genera tensión. Actuar fingiendo confianza, de forma amigable, cuando la persona está experimentando lo contrario, es una 
lucha constante. La ansiedad por no dar un paso en falso o bajar la guardia produce una tensión considerable.

Según lo señalan Rosenthal y Simeonsson en Rice (2000), las personas con baja autoestima muestran una identidad cambiante, inestable y abiertamente vulnerable a la crítica o al rechazo, lo que verifica su inadecuación, incompetencia y falta de valía. Puede que se perturben profundamente cuando piensan que se ríen de ellas, cuando sienten que las acusan o cuando perciben que otras personas tienen una opinión negativa de sí mismas. Cuanto más vulnerabilidad experimentan, mayores son sus niveles de ansiedad. Como resultado, se sienten torpes e intranquilas y evitan a toda costa exponerse al ridículo.

Santrock (2002) comenta que para muchos estudiantes y para muchas estudiantes, la autoestima baja puede ser una situación temporal. Sin embargo, para algunas y para algunos de ellos la autoestima se puede traducir en otros problemas más serios. Una pobre y persistente autoestima puede estar relacionada con el bajo rendimiento académico, la depresión y otras situaciones como la delincuencia. La seriedad de este problema depende no solo de la naturaleza de la baja autoestima del estudiante o la estudiante, sino también de otras condiciones. Por ejemplo, cuando la baja autoestima se combina con transiciones escolares difíciles o con problemas familiares, los problemas se pueden intensificar.

Una persona con baja autoestima tiene una gran sensación de inseguridad acerca de ella misma, menciona Satir (1980). Basa su autoestima, en gran parte, en lo que cree que las demás personas piensan acerca de ella, lo cual lesiona su autonomía e individualidad. En presencia de otras personas disfraza su baja autoestima, en especial cuando se propone impresionarlas. Estas personas tienen muchas esperanzas en lo que las demás pueden darles, pero a la vez tienen grandes temores, por lo que están muy expuestas a sufrir desilusiones y a desconfiar de las otras.

La baja autoestima de estas personas proviene de sus experiencias de vida, que probablemente le impidieron sentir confianza en sí misma y funcionar de manera autónoma. Al respecto, Coopersmith citado por Eisenberg y Patterson (1981, p. 70), manifiesta que: 
Esas personas carecen confianza en sí mismas y son aprehensivas acerca de expresar ideas no populares e inusuales. No desean exponerse a sí mismas, enojar a otros, o realizar acciones que podrían atraer la atención. Probablemente ellas vivan en las sombras de un grupo social, escuchan en lugar de participar y prefieren la soledad de la retirada sobre el intercambio de participación.

Considera este autor que entre los posibles factores que contribuyen a la retirada de aquellas personas con baja autoestima, está su marcada auto-conciencia y preocupación por sus problemas internos. Esa gran conciencia de sí mismas las distrae de atender a otras personas y asuntos y es probable que resulten en una excesiva preocupación por sus dificultades. El resultado es que limitan sus relaciones sociales, disminuyendo las posibilidades de vínculos de amistad y de apoyo.

Las personas con baja autoestima, indica Molina (1996), presentan características emocionales tales como agresividad, timidez, alarde, impaciencia, competitividad, arrogancia, crítica, rebeldía ante figuras de autoridad y perfeccionismo, entre otras, las cuales propician conflictos en las relaciones interpersonales.

Branden citado por de Mézerville (2004), considera que:

...una autoestima baja se correlaciona con la irracionalidad y la ceguera ante la realidad; con la rigidez, el miedo a lo nuevo y a lo desconocido; con la conformidad inadecuada o con una rebeldía poco apropiada; con estar a la defensiva, con la sumisión o el comportamiento reprimido en forma excesiva y el miedo a la hostilidad a los demás.

Agrega de Mézerville (2004) que la vivencia patológica de una autoestima pobre se manifiesta mediante una actitud de autodesprecio, vinculada con reacciones conscientes o inconscientes de autodestrucción. De esta manera, la persona que se autodesprecia, aún cuando alcance diversos logros que podrían hacerla feliz en cualquier área de su vida, renunciará a esa felicidad mediante conductas autodestructivas, pues se siente indigna de ser feliz.

Algunas actitudes habituales que indican una baja autoestima, de acuerdo con García (2005) son: 
- Autocrítica severa y excesiva que mantiene a la persona en un estado de insatisfacción consigo misma.

- Hipersensibilidad ante la crítica, por lo que se siente exageradamente atacada o herida; descarga la culpa de sus fracasos a las demás personas o a las situaciones y cultiva resentimientos persistentes contra sus críticos.

- Indecisión crónica, no por falta de información, sino por temor exagerado a equivocarse.

- Deseo innecesario por complacer, por lo que no se atreve a decir que no, por miedo a desagradar y a perder la buena opinión de otras personas.

- Perfeccionismo, autoexigencia esclavizadora de hacer perfectamente todo lo que intenta, que conduce a un desmoronamiento interior cuando las cosas no salen con la perfección exigida.

- Culpabilidad neurótica, por la que se acusa y se condena por conductas que siempre son objetivamente incorrectas. Exagera la magnitud de sus errores o los lamenta indefinidamente, sin llegar nunca a perdonarse por completo.

- Hostilidad o irritabilidad, siempre a punto de explotar aún por asuntos de poca importancia, propia de la persona supercrítica a quien todo la disgusta, la decepciona y nada le satisface.

- Tendencias defensivas, un negativismo generalizado y una incompetencia hacia el gozo de vivir y de la vida misma.

\section{La influencia de otras personas significativas en la autoestima.}

La realidad, opinan Jourard y Landsman (1987), es aquello que se considera como verdad, lo cual a su vez es influido poderosamente por lo que otras personas significativas consideran que es real e importante. Así, las otras personas pueden influir de tal forma en la manera de pensar, percibir y asignar significado y valor que tal vez se pierda la propia perspectiva. Esas personas consideradas como importantes, podrían invalidar los juicios propios de la realidad y parte de esa realidad es la persona misma.

De este modo, las creencias que sobre sí tiene la persona no se basan en conclusiones obtenidas del estudio independiente del yo, sino que se van infiriendo de lo que se escucha decir a otras personas acerca de la naturaleza propia. 
La idea de que el autoconcepto y por ende la autoestima está determinada en parte por las ideas de otras personas, o la forma en que se cree que otras personas nos perciben, es generalmente aceptada, señala Juharz en Rice (2000). No obstante, no todas las personas ejercen una influencia igualmente fuerte. Las otras personas significativas son aquellas que ocupan un alto nivel de importancia, son influyentes y sus opiniones son relevantes. Su influencia también depende de su grado de implicación y de intimidad, del apoyo social que proporcionan y del poder y autoridad que otras personas les proporcionan.

Las agencias y los agentes del proceso de socialización desempeñan un importante papel en el desarrollo de la autoestima, ya sea positiva o negativamente. Las agencias de socialización incluyen a la familia, las instituciones educativas y los medios de comunicación. Los agentes socializantes son aquellas personas que moldean la conducta de la persona en proceso de desarrollo, de modo que se ajuste a los requerimientos sociales. Así por ejemplo, los padres, madres, hermanos y hermanas, docentes e iguales son agentes de socialización. Pero a la vez, son también agentes de control social, pues controlan la conducta de la persona mediante amenazas, desaprobación o crítica; o bien, mediante la aprobación, el elogio o la recompensa. De esta manera se va definiendo en la persona su identidad, su auto concepto y la valoración que hace de sí misma.

Diversos investigadores han observado que la calidad afectiva de las relaciones familiares está asociada con altos niveles de autoestima. De acuerdo con Robinson en Rice (2000), las personas con mayor autoestima muestran una mayor intimidad con sus madres y sus padres, en otras palabras, se sienten unidos y se llevan bien con ellos y con ellas. La autoestima favorable se ha asociado con la voluntad de los padres y de las madres de premiar la autonomía, su aceptación, su flexibilidad, la comunicación, la satisfacción compartida, el apoyo y el tipo de control.

En cuanto a la influencia de los iguales en la autoestima, Golden (2005) señala que las relaciones entre los compañeros y las compañeras dentro del contexto de las instituciones educativas se presenta en gran medida como un determinante crítico del sentido de valía que el estudiante o la estudiante tiene de sí como persona. Cuando no se cuenta con el apoyo y la aprobación de los compañeros y de las compañeras y la persona es apartada o descalificada, la situación se convierte en relevante para una baja autoestima y para el sentido de valor personal. 
Si bien es cierto, el apoyo de los iguales en la clase es crítico para la autoestima, el impacto del apoyo de los profesores y las profesoras no es menos significativo. Un mayor apoyo por parte de éstos y de éstas redunda en mayores niveles de autoestima. Además, según investigaciones realizadas, se ha encontrado que una relación positiva entre los estudiantes y las estudiantes y el personal docente influencia aspectos tales como la competencia social, las actitudes generales hacia la institución educativa, las actitudes hacia las actividades educativas, el comportamiento en la sala de clase y el nivel de concentración académica.

\section{Distorsiones cognitivas}

Este es un tema propio de los enfoques cognitivos y ciertamente, señala Naranjo (2004), el rasgo común más importante que unifica esos enfoques es el énfasis que se otorga a las cogniciones, tanto en la génesis de los trastornos como en el proceso de cambio. El término cognición incluye, entre otras, ideas, imágenes, creencias y expectativas; es decir, no se refiere únicamente a un proceso intelectual, sino a procesos complejos de significado en el que participan emociones, pensamientos y conductas.

Güell y Muñoz (2000) mencionan tres principios del enfoque cognitivo. El primer principio es que son las cogniciones o pensamientos los que crean todos los estados de ánimo; es decir, la persona se siente de una manera determinada porque tiene unos pensamientos concretos. El segundo principio tiene una gran importancia: Ios pensamientos negativos que provocan un bajo nivel de autoestima son consecuencia de grandes distorsiones. Aunque esos pensamientos parecen válidos, en el fondo son irracionales o falsos. El tercer principio se deduce de los dos anteriores: si se corrigen los sistemas equivocados de pensamiento, se puede controlar, en buena medida, los estados de ánimo $y$, entre otros, la autoestima.

Las emociones traducen la manera en que se perciben las cosas. Es un hecho neurológico que antes de experimentar algo se debe procesar mentalmente y darle un significado. Si la percepción queda deformada por la mente, la respuesta emocional será desproporcionada. La persona se puede sentir mal, descontenta de sí misma, a causa de esa distorsión; esto es, la autoestima disminuye producto de un proceso mental mal estructurado. Salas (2003, p. 7) señala que: 
Las emociones son críticas para la elaboración de pautas de significado: lo que aprendemos es influido y organizado por las emociones y los conjuntos mentales que implican expectativas, inclinaciones y prejuicios personales, autoestima, y la necesidad de interacción social. Las emociones y los pensamientos se moldean unos a otros y no pueden separarse.

Por otra parte, Beck y Ellis en Naranjo (2004), señalan que las situaciones no determinan los sentimientos, sino el modo como las personas las interpretan; es decir, la respuesta emocional está condicionada por la percepción de la circunstancia.

De acuerdo con lo mencionado, se puede decir que el verdadero origen de la autoestima está en el interior de la persona. Depende de sus propias ideas, pero muchas de ellas pueden ser distorsiones cognitivas. Estos son los elementos con los que la crítica patológica ataca la autoestima. Si tuviéramos que definirlas de un modo más formal, indican Güell y Muñoz (2000, p. 120), se podría decir lo siguiente: "las distorsiones cognitivas son hábitos de pensamiento que habitualmente utilizamos para deformar negativamente la realidad".

Beck citado por Feixas y Miró (1993) y García, en Garrido y García (1994) han identificado una serie de distorsiones cognitivas, sobre las cuales se hace referencia a continuación:

- Pensamiento absolutista de tipo "todo o nada", o pensamiento dicotómico. Se manifiesta en la tendencia a ver todas las experiencias según dos posibilidades opuestas, tomando una de ellas. Por ejemplo, o soy una persona perfecta o soy un desastre.

- Sobregeneralización. Proceso de establecer una regla o conclusión general a partir de detalles que no la justifican, por tratarse de hechos aislados que no ser pueden aplicar a otras situaciones. Es decir, se elabora una regla a partir de uno o dos hechos aislados y se aplican indiscriminadamente en otras situaciones. Por ejemplo, "siempre estaré solo o sola, como esta tarde". En casos extremos, se llega a la etiquetación: "soy indeseable".

- Filtro mental o abstracción selectiva. Consiste en atender solo a los aspectos negativos de una situación, sin considerar otros aspectos aunque sean más relevantes. Por ejemplo, de un trabajo elaborado, la persona solo se fija en un 
pequeño error cometido, en lugar de valorarlo, más globalmente, en todos sus aspectos. O la persona que piensa que su vida es una calamidad porque tiene un problema afectivo, pero con una situación laboral magnífica.

- Personalización. Es la tendencia a atribuirse, sin base para ello, la responsabilidad de errores o hechos externos, o suponer que todo lo que ocurre está relacionado con uno mismo o con una misma. Por ejemplo, alguien en la familia se muestra de mal humor o triste y la persona se siente culpable pues considera que ella lo provocó.

- Sacar conclusiones precipitadas o influencia arbitraria. Se trata de llegar a conclusiones precipitadas sin disponer de datos suficientes que las apoyen. Presenta dos variantes:

- Lectura de pensamiento. Se presume tener la capacidad de saber lo que otra persona está pensando sin molestarse en comprobarlo o preguntarlo. Por ejemplo, se cree que un amigo o una amiga está decepcionado o decepcionada por algo sin haberlo hablado con él o con ella

- Rueda de la fortuna o tendencia a esperar lo peor. Se considera que algo va a salir mal antes de que haya indicios para pensarla.

Relacionado con el anterior, se encuentra el pensamiento mágico, el cual puede basarse en supersticiones negativas, el destino, entre otras. Se actúa como si los pensamientos o acciones propias fueran las que crean la realidad. Por ejemplo: "si toco madera ahuyentaré la mala suerte".

- Engrandecer o minimizar. Exagerar la importancia de unos acontecimientos en detrimento de otros. Generalmente se resta importancia a hechos positivos y se exagera la de un hecho negativo. Por ejemplo, engrandecer la importancia del éxito de un compañero o compañera y minusvalorar el propio. A veces toma la forma de pensamiento catastrófico: "esto es un desastre".

- Deberes e imperativos. Se trata de autoimposiciones que la persona se hace. Generalmente no son realistas, se autoexige más de lo que se puede dar: "debo aprobar ocho asignaturas", "debo ser amable con todas las personas", "todas las personas deben quererme sino seré desgraciado o desgraciada". Cuando los debes no se cumplen aparecen sentimientos de culpa y fracaso. 
- Descalificación de lo positivo. Se rechazan las experiencias positivas, insistiendo en que no cuentan por algún motivo. De esta forma se pueden mantener las creencias negativas a pesar de las experiencias positivas.

- El razonamiento circular, por el que un determinado hecho es causa y consecuencia a la vez de la misma situación. Por ejemplo: "no puedo vencer mi ansiedad porque soy ansioso o ansiosa".

- Las evaluaciones incorrectas acerca de lo que es seguro o peligroso, por las cuales la persona atribuye a determinadas circunstancias la categoría de peligrosas, aunque objetivamente no lo sean. Por ejemplo: "las personas frías te hacen daño"; "en los lugares abiertos no hay peligro".

- Las reglas disfuncionales sobre el bienestar y el malestar. Son creencias centradas en el tipo de condiciones para funcionar adecuadamente y sus implicaciones. Por ejemplo: "no puedo vivir sin amor, si mi pareja me deja estaré perdido o perdida". "Ser admirado o admirada es una necesidad, ser ignorado o ignorada es una maldición".

Las evaluaciones negativas hechas por el sistema cognitivo provoca en los sistemas conductual y afectivo conductas y sentimientos negativos, acordes con la interpretación realizada. Se presentan entonces conductas como la huída, la evitación o el dejar de realizar actividades, emociones como apatía, tristeza y temor, lo cual repercute en la autoestima provocando que ésta disminuya.

\section{Autoestima y resultados educativos.}

De acuerdo con Haeussler y Milicic (1995), estudios realizados sobre la relación de distintas variables con el rendimiento académico, muestran que los estudiantes y las estudiantes con autoestima positiva, altas expectativas y con motivación intrínseca para aprender, obtienen mejores logros académicos que aquellos y aquellas con autoestima baja, expectativas escasas y una motivación extrínseca para el estudio.

Asimismo, el autoconcepto académico, definido por Arancibia, Maltes y Álvarez en Jadue (2007, p. 5) como "la parte de sí mismo que se relaciona más directamente con el rendimiento académico", desempeña un papel fundamental en el rendimiento académico del estudiante y de la estudiante. 
Se menciona que la presión externa excesiva parece debilitar la autoestima y una baja se correlaciona con un menor número de intentos de superación de las dificultades y, obviamente, a menor número de intentos menos posibilidades de éxito.

Estas ideas son apoyadas por Rice (2000), quien explica que cada vez existen más datos que apoyan la teoría de que hay una correlación entre el autoconcepto y el rendimiento educativo. Los estudiantes y las estudiantes con éxito tienen un mayor sentido de valía personal y se sienten mejor consigo mismos y consigo mismas. Quienes tienen una autoestima alta tienden a tener mayor rendimiento académico y quienes realizan un potencial académico tienen una más alta autoestima. En general, a mejores notas, más posibilidad de tener una autoaceptación de alto nivel. Una razón para ello es que las personas que tienen confianza en sí mismas tienen el coraje de intentar conseguir y están motivadas para hacer realidad lo que ellas creen sobre sí mismas. Por el contrario, las personas que tienen actitudes negativas hacia sí mismas imponen limitaciones sobre su propio logro.

Se menciona asimismo, que la participación en actividades extraescolares también esta relacionada con un aumento en la autoestima. Ambas están correlacionadas, si bien no se ha podido concluir si la participación se debe a una mayor autoestima o si esa participación contribuye a una mayor autoestima. La participación en actividades extraescolares también está relacionada con mayores calificaciones y menos ausentismo a las instituciones educativas.

\section{Conclusiones}

- La autoestima es la percepción valorativa que una persona tiene hacia sí misma.

- Es un proceso dinámico y multidimensional que se construye a lo largo de la vida. Se desarrolla a partir de la interacción humana

- Contiene aspectos actitudinales, cognitivos, afectivos y conductuales.

- Mediante el autoconocimiento la persona puede lograr la autoaprobación y por consiguiente la suficiente autoestima para aceptarse a sí misma.

- Para que la persona obtenga una autoestima alta debe existir una correspondencia entre el concepto de sí misma y su yo ideal. 
- Existen una serie de aspectos interrelacionados que componen la autoestima: la autoimagen, la autovaloración, la autoconfianza, el autocontrol, la autoafirmación y la autorrealización.

- Existe una gama de conductas que se correlacionan tanto con la alta como con la baja autoestima, entre ellas: las expectativas hacia el futuro, la asertividad personal, los estilos para enfrentar el estrés, el locus de control, la toma de riesgos, el temor al fracaso y el nivel de aspiraciones.

- El autoconcepto y por ende la autoestima está determinada en parte por lo que la persona cree que otras, en especial aquellas que considera significativas, piensan de ella.

- Las cogniciones crean los estados de ánimo. Los pensamientos negativos provocan una baja autoestima y son consecuencia de distorsiones cognitivas. Si se corrige el sistema equivocado de pensamiento se puede mejorar la autoestima.

- Una autoestima pobre y persistente parece estar relacionada con el bajo rendimiento académico, la depresión y otras situaciones como la delincuencia.

- Los estudiantes y las estudiantes con actitudes negativas hacia sí imponen limitaciones para sus logros.

- El autoconcepto y por consiguiente la autoestima predice e influencia los logros en los centros educativos, desde la primaria hasta la educación universitaria.

- Los estudiantes y las estudiantes con autoconceptos claros y una autoestima positiva tienden a lograr puntajes de competencia educativa más altos.

- Facilitar el logro de autoestimas positivas en la población estudiantil debe ser una meta del proceso educativo.

\section{Referencias}

Beane, James. (1986). The self-enhancing middle-grade school. The school Counselor, 33, 89-195.

Borden, George; y Stone, John. (1982). La comunicación humana. Buenos Aires: El Ateneo.

De Mézerville, Gastón. (2004). Ejes de salud mental. Los procesos de autoestima, dar y recibir afecto y adaptación al estrés. México: Trillas.

Eisenberg, Sheldon and Patterson, Lewis. (1981). Helping clients with special concerns. Chicago: Rand Mc Nally College Publishing Company. 
Feixas, Guillén y Miró, María Teresa. (1993). Aproximaciones a la psicoterapia. Una introducción a los tratamientos psicológicos. Barcelona: Paidós.

García, Verónica. (2005). Autoestima. Recuperado el 22 de marzo del 2007, de www.pino.pntic.mec./recursos/infantil/salud/autoestima.htm.

Garrido, Miguel; y García Jesús. (1994) Psicoterapia. Modelos contemporáneos y aplicaciones. Valencia: Promolibro.

Güell, Manuel y Muñoz, Josep. (2000). Desconócete a ti mismo. Programa de alfabetización emocional. Barcelona. Paidós.

Haeussler, Isabel y Milicic, Neva. (1995). Confiar en uno mismo. Programa de desarrollo de la autoestima. Santiago: Dolmen.

Jadue, Gladys. (2001). Estudios pedagógicos. Recuperado el 14 de abril de 2007 de Http://www.scielo.php?pid=50718-0705200100010008script=sci-arttext.

Jourard, Sidney y Landsman, Ted. (1987). La personalidad saludable. El punto de vista de la psicología humanista. México: Trillas.

Lee, Dan. (1986). The effect of two methods of affective education on self-concept in seventh-grade students. The School Counselor, 18, 123-134.

Molina, Margarita; Baldares; Thelma y Maya, Arnobio. (1996). Fortalezcamos la autoestima y las relaciones interpersonales. San José: Impresos Sibaja.

Naranjo, María Luisa. (2004). Enfoques conductistas, cognitivos y racional emotivos. San José: Universidad de Costa Rica.

Olivares, María Mercedes; Sequeira, Nuria; Solano, Margarita y Vargas, Rosa María. (1998). Programa de orientación personal para el fortalecimiento de la autoestima en docentes. Tesis para optar por el grado de Licenciatura en Ciencias de la Educación con énfasis en Orientación, Universidad de Costa Rica, San José, Costa Rica.

Programa Golden 5: Una intervención psicoeducativa. (2005). Recuperado el 14 de abril de 2007 de http://www.golden5.org

Rice, Philip. (2000). Adolescencia. Desarrollo, relaciones y cultura. Madrid: Prentice Hall.

Salas, Raúl. (2003). ¿La educación necesita realmente de la neurociencia? Estudios pedagógicos. (29), 155-171.

Santrock, John. (2002). Psicología de la educación. México: Mc Graw Hill.

Satir, Virginia. (1980). Psicoterapia familiar conjunta. México: Prensa Médica Mexicana. 